\title{
Investigation of the Influence of Different Modifiers on the Eutectic Si in the Composition of AlSi18 Alloy
}

\author{
Ivan Panov \\ Technical University - Sofia, Plovdiv \\ Branch \\ Plovdiv, Bulgaria \\ specialista57@abv.bg
}

\author{
Boyan Dochev \\ Technical University - Sofia, Plovdiv \\ Branch \\ Plovdiv, Bulgaria \\ boyan.dochev@gmail.com
}

\author{
Valentin Manolov \\ Institute of Metal Science, \\ Equipment, and Technologies "Acad. \\ A. Balevski” with Center for Hydro- \\ and Aerodynamics at the Bulgarian \\ Academy of Sciences \\ Sofia, Bulgaria \\ v.manolov@ims.bas.bg
}

\author{
Angel Velikov \\ Institute of Metal Science, \\ Equipment, and Technologies "Acad. \\ A. Balevski" with Center for Hydro- \\ and Aerodynamics at the Bulgarian \\ Academy of Sciences \\ Sofia, Bulgaria \\ anmabg@abv.bg
}

\author{
Vanya Dyakova \\ Institute of Metal Science, \\ Equipment, and Technologies "Acad. \\ A. Balevski" with Center for Hydro- \\ and Aerodynamics at the Bulgarian \\ Academy of Sciences \\ Sofia, Bulgaria \\ v_diakova@mail.bg
}

\begin{abstract}
The structure of hypereutectic aluminum-silicon alloys consists of primary silicon crystals arranged in a eutectic matrix. In the present work the influence of different types of modifiers on the size and shape of the silicon crystals in the composition of the eutectic of the AISi18 alloy has been studied. The classic for this type of alloys modifier (phosphorus), as well as the nanomodifiers $\mathrm{SiC}$ and nanodiamonds (ND) have been used. The results of the microstructural analysis show that the three modifiers used affect differently the shape and size of the eutectic silicon of the investigated alloy.
\end{abstract}

Keywords - hypereutectic aluminum-silicon alloy, modification, nanomodifiers, eutectic silicon

\section{INTRODUCTION}

Hypereutectic aluminum-silicon alloys are characterized by good mechanical properties, wear resistance, corrosion resistance and low coefficient of linear expansion. These are the main reasons why such alloys are the preferred material for making pistons for internal combustion engines. The primary silicon crystals in unmodified hypereutectic aluminum-silicon alloys are in the range of $80-100 \mu \mathrm{m}$ and have a rough irregular shape. Therefore, they have a strong notching effect on the structure of the alloys and significantly impair their mechanical and operational properties. In order to increase the mechanical properties of the alloys, it is necessary to grind the primary silicon crystals, to ensure their uniform distribution in the structure of the alloy and to give them a compact shape, thereby reducing their notching action. This is achieved by a modifying mode of treating the alloys. Apart from the modification of the primary silicon crystals, in order to increase the properties of this type of alloys, it is necessary to strengthen the eutectic matrix in which they are located, i.e. the silicon crystals in the eutectic composition must also be modified. The published studies, based on a two-stage type of modifying treatment of hypereutectic aluminum-silicon alloys, using phosphorus and sodium (sulfur and sodium), show unsatisfactory results due to the formation of $\mathrm{NaP}$ or $\mathrm{NaS}$ and loss of the modifying effect of the used modifiers, which necessitates other solutions to be searched. [1].

To modify the $\alpha$-phase in the composition of the eutectic in the structure of hypoeutectic and eutectic 
aluminum-silicon alloys, new types of modifiers nanomodifiers - have recently been used. These modifiers work in the alloys as surfactants (modifiers of the first order); they block the growth of the $\alpha$-phase and, accordingly, of the silicon crystals in the eutectic, so the silicon crystals get refined for this reason as well [2], [3], [4]. , [5], [6], [7], [8], [9], [10]. This is a prerequisite for the use of such modifiers to treat the eutectic, on the one hand, and to treat hypereutectic aluminum-silicon alloys in order to modify the eutectic silicon crystals in them,

\section{MATERIALS AND METHODS}

The object of study in this work was a two-component hypereutectic aluminum-silicon alloy AlSi18. The content of alloying elements in the composition of the alloy was minimized, and the impurity elements were insignificant. This was done in order to obtain results that can only be explained by the action of the used different types of modifiers on the structure of the studied alloy. The chemical composition of the alloy is shown in Table 1.

The following modifiers were used to modify the investigated alloy: phosphorus (0.04wt\%), nanomodifier $\mathrm{SiC}$ ( $\beta$-modification) in the amount of $0.1 \mathrm{wt} \%$, and nanodiamonds (ND) nanomodifier in the amount of $0.1 w t \%$. Phosphorus was introduced into the melt of the investigated alloy by the ligature $\mathrm{CuP} 10, \mathrm{SiC}$ - in the form of an aluminum composite rod, and the ND nanomodifier was packed in the form of an aluminum cartridge. For better wetting and absorption by the melt, the nanoscale modifiers are coated with various metal protectors. The $\mathrm{SiC}$ nanomodifier, used in this case, was Cu-coated and the ND nanomodifier - plated with $\mathrm{Ni}$.

TABLE 1 CHEMICAL COMPOSITION OF ALSi18 ALLOY

\begin{tabular}{|c|c|c|c|c|c|c|}
\hline $\mathrm{Si}$ & $\mathrm{Cu}$ & $\mathrm{Mn}$ & $\mathrm{Mg}$ & $\mathrm{Cr}$ & $\mathrm{Fe}$ & $\mathrm{Al}$ \\
\hline 17,6 & 0,03 & 0,05 & 0,001 & 0,001 & 0,12 & rest \\
\hline
\end{tabular}

Experiments were conducted with unmodified AlSi18 alloy, as well as with the same alloy, modified by $\mathrm{P}, \mathrm{SiC}$ and ND. To ensure comparability of the obtained results, all experiments were performed under the same conditions. The alloys were refined with a coating refining flux in the amount of $0.5 \mathrm{wt} \%$ of the amount of the alloy, the melts were degassed by blowing with argon for $3 \mathrm{~min}$ at a temperature of $760^{\circ} \mathrm{C}$, and the modifying treatment was carried out at a temperature of $810^{\circ} \mathrm{C}$. The casting temperature of the investigated compositions was $760^{\circ} \mathrm{C}$, and the temperature of the used metal equipment $-210^{\circ} \mathrm{C}$. Sections for microstructural analysis were prepared from the cast test samples.

\section{RESULTS AND DISCUSSION}

The results of the microstructural analysis show that the silicon crystals in the eutectic composition of the unmodified AlSi18 alloy are up to 250-260 $\mu \mathrm{m}$ long and are in the form of well-shaped elongated plates, looking like needles in the plane of the microscopic observation
(Fig. 1). There are also small silicon crystals with a size of several microns, which form groups or are located next to each other and at small microscopic magnifications resemble a broken needle (Fig. 2). In another area of the microscopic field, fine silicon crystals can be seen, resembling a "fishbone" (Fig. 3). Particles with a shape, characteristic of non-metals, are observed in the eutectic (Fig 4).

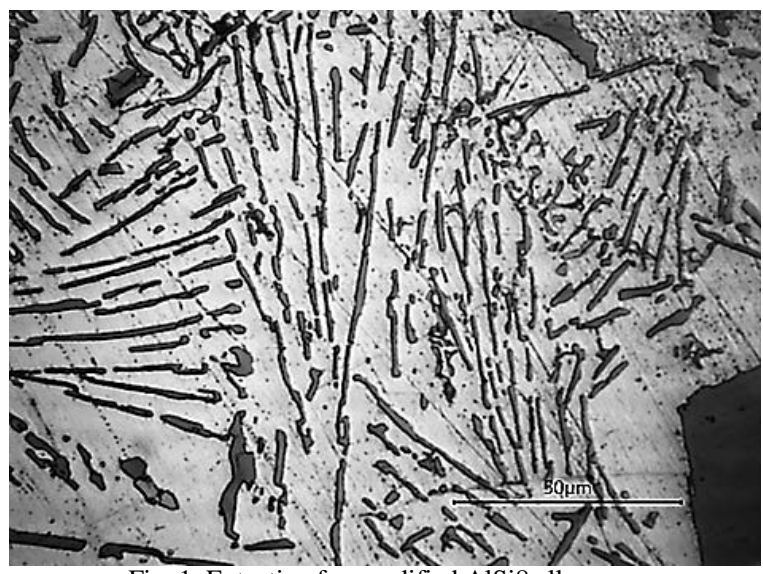
Fig. 1. Eutectic of unmodified AlSi8 alloy

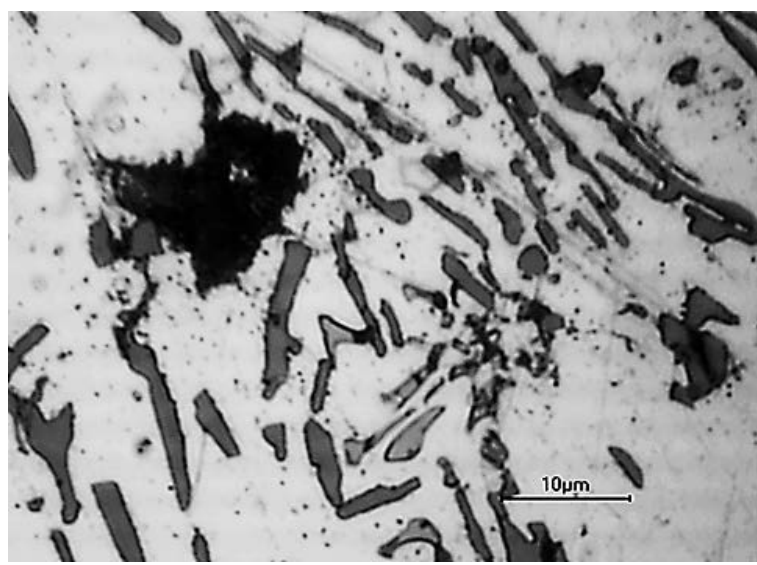

Fig. 2. Eutectic of unmodified AlSi8 alloy 


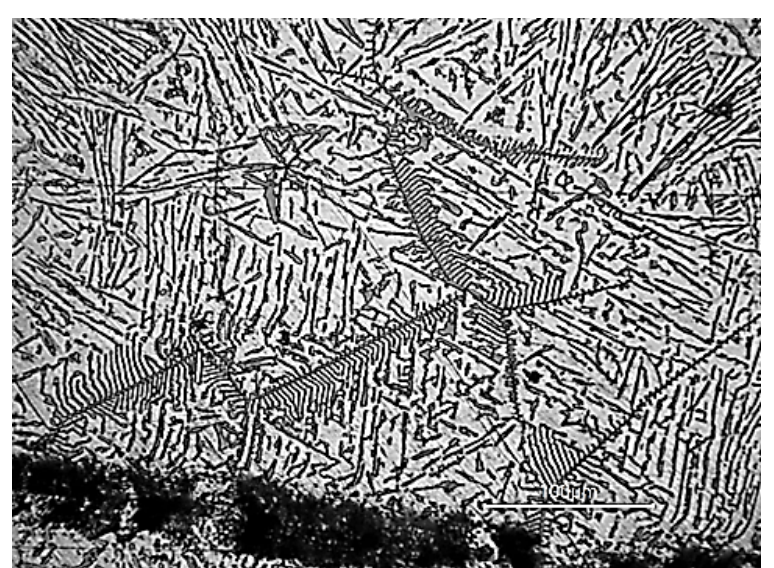

Fig. 3. Eutectic of unmodified AlSi8 alloy



The silicon crystals in the eutectic composition of the phosphorus-modified hypereutectic aluminum-silicon alloy AlSi18 are refined. They are in the form of plates (needles) and reach a length of 115-135 $\mu \mathrm{m}$ (Fig. 5). There are also small rounded silicon crystals, which are like clusters and resemble broken needles (Fig. 6). Given that modifiers most often have a double action, we assume that (P) could also be adsorbed at the grain boundaries of the alpha phase (solid solution of silicon in aluminum), not allowing the grains of the alpha phase to increase this way, which means that phosphorus has an impact on the structure as a modifier of the first order as well. Due to the prevention of the alpha-phase grains from growth, the distances between the branches of the dendrites remain small, and this is exactly where the discrete silicon crystals are distributed during the formation of the eutectic. In our opinion, this is the reason why phosphorus $(\mathrm{P})$ influences the size of the silicon crystals in the composition of the eutectic of the studied alloy as well.

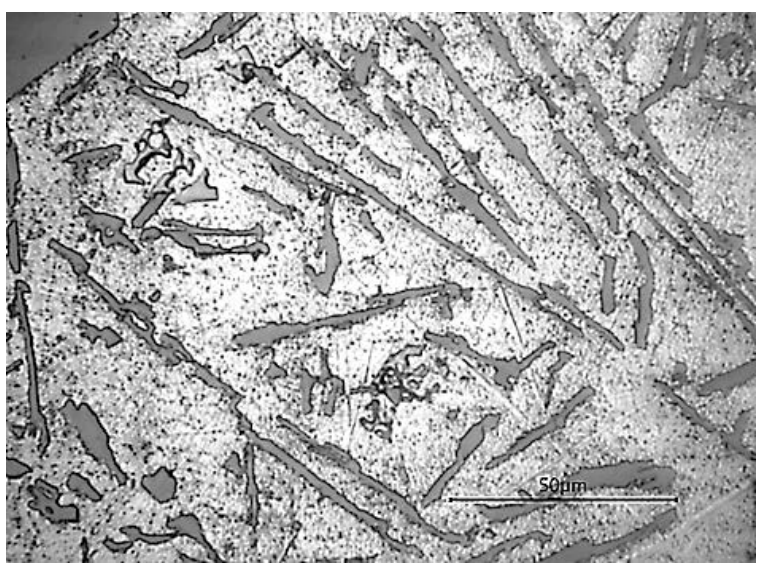

Fig. 5. Eutectic of phosphorus-modified AlSi18 alloy

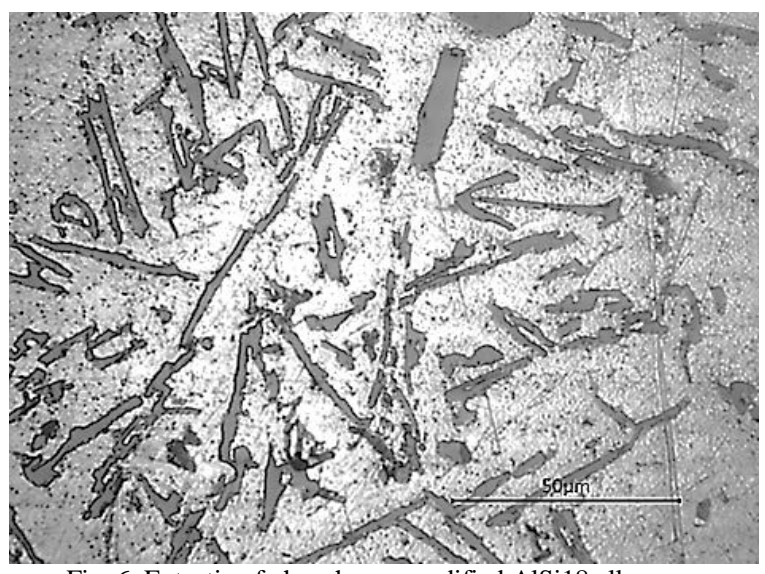

Fig. 6. Eutectic of phosphorus-modified AlSi18 alloy

After the microstructural analysis of the hypereutectic aluminum-silicon alloy AlSi18, modified by the nanomodifier $\mathrm{SiC}$, the results show that the silicon crystals in the composition of the eutectic are very small, and whole "needles" rarely occur. Most often there are a series of small silicon crystals arranged next to each other, not longer than 4-5 $\mu \mathrm{m}$ (Fig. 7 and Fig. 8). It can be assumed that the nanomodifier ( $\mathrm{SiC}$ ) is adsorbed at the grain boundaries of the alpha phase, thus inhibiting the growth of the alpha crystals, and, in result of concentration fluctuations, many silicon crystals are formed on the branches of the dendrites, also not having the chance to significantly increase their size. This is most likely the reason why the silicon crystals in the eutectic are so highly refined. 

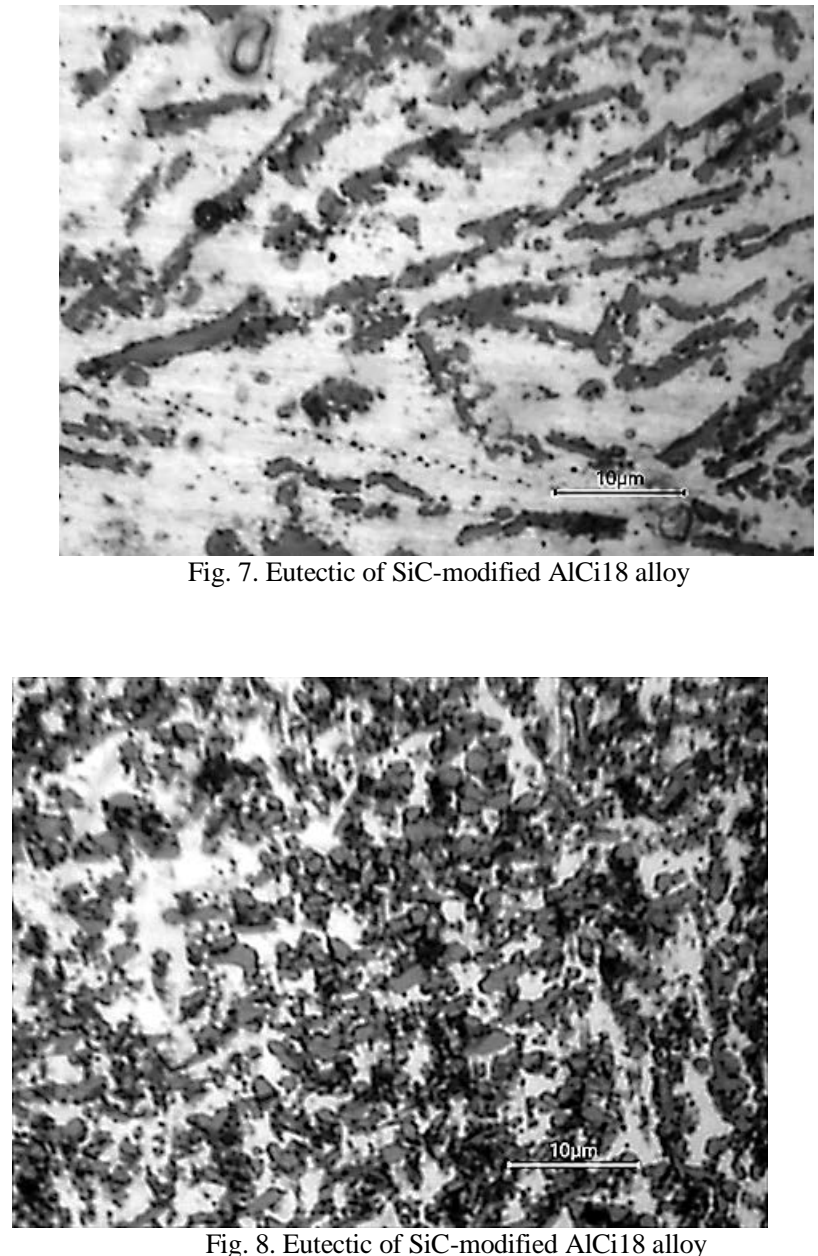

In the hypereutectic aluminum-silicon alloy AlSi18, modified by a ND nanomodifier, the silicon crystals in the eutectic composition are significantly refined. The amount of silicon in the form of plates (needles) is insignificant, their average maximum length is about 15-16 $\mu \mathrm{m}$. However, the share of small equiaxed silicon particles increases (Fig. 9 and Fig. 10). Given the claim that some of the modifiers, used to modify aluminum-silicon alloys, have a double action, we can assume that the nanodiamond (ND) nanomodifier is a complex modifier, i.e., it has a modifying effect both on the crystals of primary silicon and on the alpha phase in the composition of the eutectic, respectively on the silicon crystals in the composition of the eutectic as well. This is a prerequisite for the structureformation process of the studied hypereutectic aluminumsilicon alloy AlSi18, modified by a nanodiamonds (ND) nanomodifier, to proceed in accordance with both the adsorption theory and the theory of overcooling at the same time.

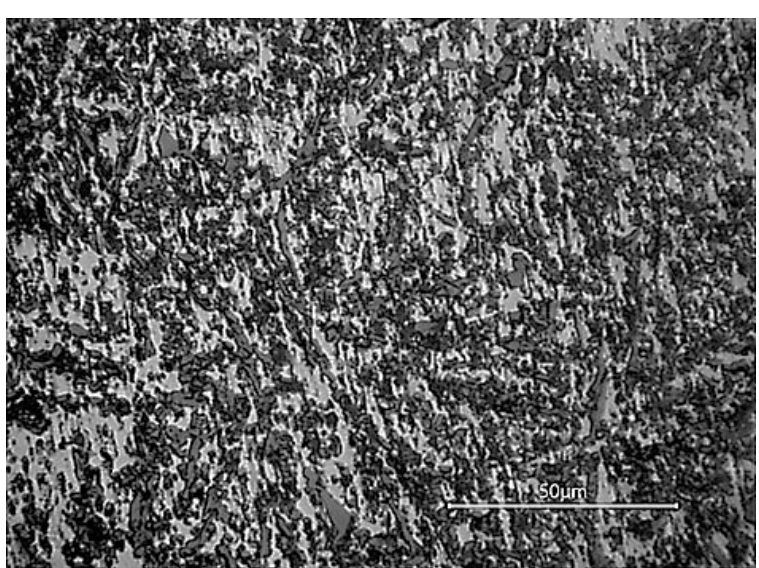

Fig. 9. Eutectic of ND-modified AlSi18 alloy

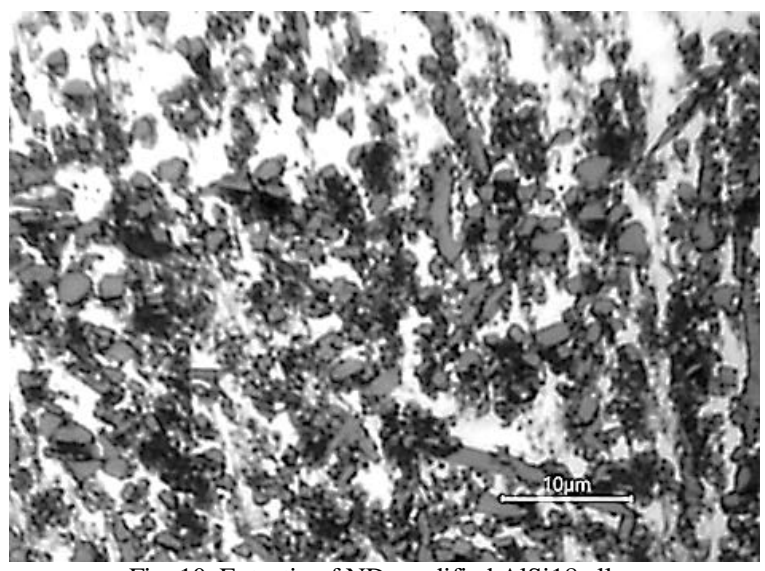

Fig. 10. Eutectic of ND-modified AlSi18 alloy

Table 2 shows the results from the performed microstructural analysis of the studied AlSi18 alloy in unmodified and modified state.

TABLE 2 RESULTS OF MICROSTRUCTURAL ANALYSIS

\begin{tabular}{|c|c|c|c|c|}
\hline Modifier & - & $\mathrm{P}$ & $\mathrm{SiC}$ & ND \\
\hline $\begin{array}{l}\text { Size of Si in the } \\
\text { composition of the } \\
\text { eutectic }\end{array}$ & $\begin{array}{l}250- \\
260 \\
\mu \mathrm{m}\end{array}$ & $\begin{array}{l}115- \\
135 \\
\mu \mathrm{m}\end{array}$ & $\begin{array}{l}4-5 \\
\mu \mathrm{m}\end{array}$ & $\begin{array}{c}15- \\
16 \\
\mu \mathrm{m}\end{array}$ \\
\hline
\end{tabular}

\section{CONCLUSIONS}

It has been proven that the classic modifier $(\mathrm{P})$ affects the shape and size of the primary silicon crystals in the structure of the investigated hypereutectic alloy. Moreover, the conducted studies show that it also has a modifying effect on the size of the silicon crystals in the composition of the eutectic of the AlSi18 alloy.

The modifier SiC has the strongest modifying effect on the silicon crystals in the composition of the eutectic. It affects both their size and their shape, having a pronounced compacting effect on the eutectic silicon in the structure of the studied alloy.

The nanodiamond ND modifier also considerably affects the size of the eutectic silicon crystals. In addition 
to the significant reduction in their size, we find again a tendency toward globulisation and compaction of the eutectic silicon crystals, similar to the case when the AlSi18 alloy is modified by SiC. We can assume that the reason behind this similar action of the $\mathrm{SiC}$ modifier and the nanodiamonds is hidden in their size (20-50 nm).

Acknowledgments: The authors would like to thank the Research and Development Sector at the Technical University of Sofia for the financial support

\section{REFERENCES}

[1] G.B Stroganov, B.A.Rotenberg, G.B.Gershman, Alloys of aluminum with silicon, M., Metallurgy, 1977 (In Russian);

[2] V. Manolov, A.Cherepanov, R. Lazarova and S. Konstantinova, March, 22-25, 2011, Properties of the aluminium alloy AlSi7Mg, modified by refractory nanopowders, Interaction of highly concentrated energy flows with materials in promising technologies and medicine, IVth all-Russan conference, Novosibirsk, 186-190, ISBN 9785-93089-034-1

[3] R. Lazarova, N. Bojanova, R. Dimitrova, I. Panov and V. Manolov, Influence of Nanoparticles Introducing in the Melt of Aluminum Alloys on Castings Microstructure and Properties, https://ink.springer.com/article/10.1007/s40962-016-0033-7

[4] V. Manolov, A. Cherepanov, R. Lazarova, and S. Konstantinova, Influence of nanopowder inoculars on the structure and the properties of the AlSi7Mg alloy, Foundry, M., № 11, 11-14, ISSN: 0024-449X, IF 0,088
[5] R. Lazarova, V. Gaidarova, V. Manolov, M. Manchev, S. Konstantinova, A. Cherepanov, Investigation of the influence of modifying nanopowders on the characteristics of metal alloys. Proceedings of the VII International Scientific-Technical Congress "Machines, Technologies, Materials" - MTM'2010, Sofia, Bulgaria, May 2010, 48-53.

[6] V N Gaidarova, R L Lazarova, S V Vaseva, V K Manolov, and S G Konstantinova, June 2010, Microstructure and Mechanical Properties of AlSi7Mg Alloy: Effect of Added Nanodiamond, In: Explosive Production of New Materials: Science, Technology, Business, and Innovations. Edited by A.A. Deribas and Yu.B. Scheck, Moscow, TORUS PRESS, ISBN 978-5-94588-073-3, p. 25 (Proceedings of the X International Symposium EPNM-2010 Bechichi, Montenegro)

[7] S. Iman El-Mahallawi, Ahmed Yehia Shash and Amer Eid Amer, Metals 2015, 5(2), 802-821; Nanoreinforced Cast Al-Si Alloys with $\mathrm{Al} 2 \mathrm{O} 3, \mathrm{TiO} 2$ and $\mathrm{ZrO} 2$ Nanoparticles, doi:10.3390/met5020802

[8] Hongseok Choi, Hiromi Konishi, Xiaochun Li. Al2O3 nanoparticles induced simultaneous refinement and modification of primary and eutectic Si particles in hypereutectic Al-20Si alloy. Materials Science and Engineering A 541 (2012) 159- 165 (Department of Mechanical Engineering, University of WisconsinMadison, Madison, WI 53706, USA)

[9] El-Mahallawi, H.Abdelkader, L.Yousef, A.Amer, J.Mayer, A.Schwedt Influence of Al2O3 nano-dispersions on microstructure features and mechanical properties of cast and T6 heat-treated AlSi hypoeutectic Alloys. Materials Science\&Engineering A 556 (2012) 76-87.

[10] K.. Borodianskiy, A. Kossenko, M. Zinigrad, Improvement of the mechanical properties of $\mathrm{Al}-\mathrm{Si}$ alloys by $\mathrm{TiC}$ nanoparticles, Metallurgical and Materials Transactions A, Nov. 2013, Vol.44, Iss.11, pp 4948-4953. 